major oncology centre. If the management is directed by the major centre there should be an adequate check on standards and back up in the event of complications.

Worthing Hospital

Worthing,

West Sussex BN11 2DH

1 Holyoake TL, Franklin IM. Bone marrow transplants from peripheral blood. $B M F$ 1994;309:4-5. (2 July.)

\section{Outcomes research in clinical practice}

\section{Descriptive studies are unhelpful}

EDrToR,-In the issue that included an editorial discussing the importance of outcome research in clinical practice, ${ }^{1}$ the paper by D J Houghton and colleagues concluded that "general practitioners should no longer request sinus radiography" without measuring any outcomes at all. ${ }^{2}$

This was a descriptive study in which local general practitioners' knowledge of indications for sinus radiography was assessed. The authors extrapolated the fact that half the population have minor changes on such radiographs and concluded that the indications given were worthless. The requests perceived as due to patient pressure were dismissed on the grounds that general practitioners should invoke the college guidelines. Studies have shown that using the guidelines reduces the number of referrals, ${ }^{3}$ but in an age of patient's rights it is difficult to dissuade a demanding patient completely.

A more appropriate method would have been to examine the actual requests received by a radiography department and measure the outcomes of these in terms of radiological findings, clinical outcomes, and patient satisfaction. Apart from principals answering a questionnaire, the general practice input is non-existent and consequently is unlikely to change clinical practice. ${ }^{4} \mathrm{As}$ it is, the authors should remember that a descriptive study has the weakest methodological rigour and is certainly not the basis for such sweeping conclusions.

MICHAEL GREGORY

Medical Centre,

Rhine Centre,

Dusseldorf,
BFPO 34

1 Delamothe T. Using outcomes research in clinical practice. $B M F$ 1994;308:1583-4. (18 June.)

2 Houghton DJ, Aitchison FA, Wilkinson L, Wilson JA. Use of sinus $x$ ray films by general practitioners. $B M 7$ 1994;308. 1608-9. (18 June.)

3 Oakshot P, Kerry S, Williams J. Randomised controlled trial of the Royal College of Radiologists' guidelines on general the Royal College of Radiologists guidelines on general
practitioners referrals for radiographic examination. $\mathrm{Br} ₹ \mathrm{Gen}$ practitioners referrals

4 MacAuley D. READER: an acronym to aid critical reading by general practitioners. $B r f$ Gen Pract 1994;44:83-5.

\section{Patients' views ignored}

EDITOR,-Andrew Haines and Roger Jones give a welcome reminder of the importance of implementing findings of research into medical practice. If it is true, as has been suggested, ${ }^{2}$ that no more than $15 \%$ of all practice within the NHS has been properly evaluated, there is a long way to go before we can claim with any confidence that the health service is demonstrably cost effective.

However, there is a serious bias in the article. In all the examples given and strategies suggested it is implicit that the experts decide what is effective treatment and that health professionals are then suitably persuaded to change practice (sometimes by the indirect route of informing the public of research results). What is missing is the involve- ment of patients and public in assessing the outcomes of care in the first place. The conference on outcomes research in clinical practice noted that the list of possible groups concerned with outcomes failed to mention patients at all. ${ }^{3}$ The bias against including patients' experience seems pervasive.

There is one area of developing practice where this bias is apparent and particularly topical: the use of counselling in general practice. A review last year stated that "many attempts to evaluate its effectiveness have shown little or no benefit,"4 and this is the tone of many such reviews in the medical press. Such a conclusion is seriously at odds with the positive experience of patients and doctors in practices where counselling is provided.

In fact there is good evidence of benefits from a systematic meta-analysis of all British studies of counselling in general practice that fit precise selection criteria." It is possible that the review articles are seriously biased in not taking into account subjective experience and in considering only benefits at longer term follow up at one or two years. The value of counselling, which may be rapidly apparent to patients and general practitioners, could be reduced for many patients with self limiting emotional problems. Neither general practitioners nor patients are likely to accept that weakening effects over time are a justification for declaring such treatments as ineffective.

FRANK LEDWTTH

St Martin's College,

Senior lecture

Lancaster KA1 3JD

DAVID LYON

Castlefields Health Centre,

eneral practitioner

Chester Close,

Runcorn WA7 2HY

1 Haines A, Jones R. Implementing findings of research. $B M \Im$ 1994;308:1488-93. (4 June.)

2 Smith R. Where is the wisdom ... ? BMY 1991;303:798-9.

Delamothe $\mathrm{T}$. Using outcomes research in clinical practice. $B M J$ 1994;308:1583-4. (18 June.)

4 Pringle $M$, Laverty $M$. A counsellor in every practice? $B M F$ 1993;306:2-3.

5 Balestrieri M, Williams P, Wilkinson G. Special mental health treatment in general practice: a meta-analysis. Psychol Med 1988;18:711-7.

\section{Use of benzodiazepines}

EDrroR,-Neil Wright and colleagues report a $0.5 \%$ point prevalence in a single general practice for prescribing of benzodiazepine anxiolytics taken during the day.' Furthermore, they found that almost half the patients in their study wished to continue taking benzodiazepines.

However, the level of prescribing of benzodiazepines may reflect the policies of only the general practitioners concerned. We are currently carrying out a study of benzodiazepine prescribing in 16 Liecestershire practices, total population 117096 , and have found wide variation in the prevalence of long term benzodiazepine users between practices. The range for users of anxiolytic benzodiazepines was $0.3 \%$ to $1.9 \%$, and for users of hypnotic or anxiolytic drugs was $0.6 \%$ to $3.9 \%$ of the practice populations, indicating that the practice in the study reported by Wright and colleagues had a relatively low proportion of long term users.

Patients in our study were classed as chronic benzodiazepine users if they had taken the drug for longer than one month, to accord with the Committee on the Safety of Medicines' guidelines, which state that benzodiazepines should be prescribed for only two to four weeks. ${ }^{2}$ Although this cut off point is earlier than that of Wright and colleagues, this cannot account for the difference in prevalence levels as $96 \%$ of the patients in our study had been taking the drug for more than a year.

Our study has identified a total of 2178 long term benzodiazepine users (hypnotic or anxiolytic). Even if only half of these want to stop taking their medication, as indicated by Wright and colleagues, we have found just over 1000 patients from 16 practices who may benefit from being offered assistance with withdrawal. Therefore it would be unwise to imply that withdrawal programmes are not required.

RICHARD H BAKER

Director

CLARE TAIT

Research assistant

Eli Lilly National Clinical Audit Centre,

Leicester General Hospital

Leicester LE5 4PW

Leicester

1 Wright N, Caplan R, Payne S. Community survey of long term daytime use of benzodiazepines. $B M F$ 1994;309:27-8. (2 July.)

2 Committee on the Safety of Medicines. Benzodiazepines: dependency and withdrawal symptoms. Current Problems 1988;21:1-2.

\section{Health needs of elderly people}

EDITOR,-In her editorial on priorities in geriatric research, Christine K Casel states that the world's elderly population is increasing dramatically and most visibly in "developed" countries." This reflects our society's myopia with respect to the health of those in so called "developing" countries, where the majority of the world's elderly live.

The world population aged over 55 years increases by one million people per month. Eighty per cent of growth is in developing countries where, by the year 2020 , the elderly population is likely to exceed one billion. Over the next 30 years the proportion of the world's elderly population living in developing countries is projected to increase from $58 \%$ to $72 \% .^{2}$ Current public health policies in many Third World countries, supported by international agencies, focus on maternal health, contraception, and infant health. The result will be the aging of society in Africa, Asia, and South America, and chronic, non-communicable diseases in these populations will become a prime health concern.

Is this not evidence enough to support the urgent need for research into the health care needs of elderly people worldwide? We must be less parochial if we wish to address the genuine needs of the world's elderly population. The effects of demographic changes on patterns of health demand that we formulate plans to deal with the associated medical problems in rich and poor countries alike.

TJASPRAY
First assistant in medicine of the elderly

Department of Medicine (Geriatrics)

Medical School,

University of Newcastle upon Tyne,

Newcastle NE2 4HH

1 Cassel CK. Researching the health needs of elderly people. $B M \mathcal{I}$ 1994;308:1655-6. (25 June.)

2 Kinsella K. Aging in the Third World. Washington, DC: Bureau of the Census, US Department of Commerce, 1988.

\section{Management of mild dyskaryosis}

EDITOR,-Flannelly and colleagues, ${ }^{1}$ Soutter and Fletcher, $^{2}$ and Hammond ${ }^{3}$ all recommend immediate colposcopic referral for mild dyskaryosis. This policy would have significant implications for the colposcopy workload, and although immediate referral would reduce the volume of pre-colposcopic surveillance, colposcopy itself often leads to frequent follow up smears. Selective referral according to smoking habit is an increasing possibility and might have public health benefit. In any event, continuing education about cervical 